\title{
Inference of a Common Fixed Point Theorem on Four Self Maps
}

\author{
V.Srinivas \\ Department of Mathematics, \\ Sreenidhi Institute of Science and Technology, \\ Ghatkesar, Hyderabad, India-501 301
}

\author{
R.Umamaheshwar Rao \\ Department of Mathematics, \\ Sreenidhi Institute of Science and Technology, \\ Ghatkesar, Hyderabad, India-501 301
}

\begin{abstract}
:
The aim of this paper is to prove a common fixed point theorem which generalizes the result of Brian Fisher [1] and etal. by weaker conditions. The conditions of continuity, compatibility and completeness of a metric space are replaced by weaker conditions such as weakly compatible and the associated sequence.
\end{abstract}

\section{KEYWORDS:}

Fixed point, self maps, compatible maps, weakly compatible mappings, associated sequence.

\section{INTRODUCTION}

Two self maps $\mathrm{S}$ and $\mathrm{T}$ are said to be commutative if $\mathrm{ST}=\mathrm{TS}$ The concept of the commutativity has been generalized in several ways. For this Gerald Jungck [2] initiated the concept of compatibility.

\subsection{Compatible Mappings:}

Two self maps $\mathrm{S}$ and $\mathrm{T}$ of a metric space $(\mathrm{X}, \mathrm{d})$ are said to be compatible mappings if $\lim _{\mathbf{n} \rightarrow \infty} \mathrm{d}\left(\mathrm{STx}_{\mathrm{n}}, \mathrm{TSx}_{\mathrm{n}}\right)=0$, whenever $\left\langle\mathrm{x}_{\mathrm{n}}\right\rangle$ is a sequence in $X$ such that $\lim _{n \rightarrow \infty} S x_{n}=\lim _{n \rightarrow \infty} T x_{n}=t$ for some $t \in X$

It can be easily verified that when the two mappings are commuting then they are compatible but not conversely.

In 1998, Jungck and Rhoades [4] introduced the notion of weakly compatible and showed that compatible maps are weakly compatible but not conversely.

\subsection{Weakly Compatible:}

A pair of maps $\mathrm{A}$ and $\mathrm{S}$ is called weakly compatible pair if they commute at coincidence points.

Brian Fisher and others [1] proved the following common Fixed Point theorem for four self maps of a complete metric space.

Theorem 1.3 Suppose A, B, S and T are four self maps of metric space $(\mathrm{X}, \mathrm{d})$ such that

1.3.1 (X,d) is a complete metric space

1.3.2 $\mathrm{A}(\mathrm{x}) \subset \mathrm{T}(\mathrm{x}), \mathrm{B}(\mathrm{x}) \subset \mathrm{S}(\mathrm{x})$

1.3.3 The pairs $(\mathrm{A}, \mathrm{S})$ and, $(\mathrm{B}, \mathrm{T})$ are compatible

1.3.4 d $(\mathrm{Ax}, \mathrm{By})^{2}<\mathrm{c}_{1} \max \left\{\mathrm{d}(\mathrm{Sx}, \mathrm{Ax})^{2}, \mathrm{~d}(\mathrm{Ty}, \mathrm{By})^{2}, \mathrm{~d}(\mathrm{Sx}, \mathrm{Ty})^{2}\right\}$

\author{
$+\mathrm{c}_{2} \max \{\mathrm{d}(\mathrm{Sx}, \mathrm{Ax}) \mathrm{d}(\mathrm{Sx}, \mathrm{By}), \mathrm{d}(\mathrm{Ax}, \mathrm{Ty}) \mathrm{d}(\mathrm{By}, \mathrm{Ty})\}$ \\ $+c_{3}\{d(S x, B y) d(T y, A x)\}$ \\ Where $c_{1}, c_{2}, c_{3} \geq 0, c_{1}+2 c_{2}<1$ and $c_{1}+c_{3}>1$, then A,B,S and T \\ have a unique common fixed point $\mathrm{z} \in \mathrm{X}$.
}

\subsection{Associated Sequence:}

Suppose A, B, S and T are self maps of a metric space (X, d) satisfying the condition (1.3.2), Then for any $\mathrm{x}_{0} \in \mathrm{X}, \mathrm{Ax_{0 }} \in \mathrm{A}(\mathrm{X})$ and hence, $A x_{0} \in T(X)$ so that there is a $x_{1} \in X$ with $A x_{0}=T_{1}$. Now $\mathrm{Bx}_{1} \in \mathrm{B}(\mathrm{X})$ and hence there is $\mathrm{x}_{2} \in \mathrm{X}$ with $\mathrm{Bx}_{1}=\mathrm{Sx}_{2}$. Repeating this process to each $\mathrm{x}_{0} \in \mathrm{X}$, we get a sequence $\left\langle\mathrm{x}_{\mathrm{n}}\right\rangle$ in $X$ such that $\mathrm{Ax}_{2 \mathrm{n}}=\mathrm{Tx}_{2 \mathrm{n}+1}$ and $\mathrm{Bx}_{2 \mathrm{n}+1}=\mathrm{Sx}_{2 \mathrm{n}+2}$ for $\mathrm{n} \geq 0$. We shall call this sequence as an associated sequence of $\mathrm{x}_{0}$ relative to the four self maps A, B,S and T.

Now we prove a lemma which plays an important role in proving our theorem.

1.5 Lemma: Suppose A, B, S and T are four self maps of a metric space $(\mathrm{X}, \mathrm{d})$ satisfying the conditions (1.3.2) and (1.3.4) of Theorem(1.3) and Further if (1.3.1) (X, d) is a complete metric space then for any $\mathrm{x}_{0} \in \mathrm{X}$ and for any of its associated sequence $\left\langle\mathrm{x}_{\mathrm{n}}\right\rangle$ relative to Four self maps, the sequence $\mathrm{Ax}_{0}, \mathrm{Bx}_{1}, \mathrm{Ax}_{2}, \mathrm{Bx}_{3}, \ldots \ldots \ldots, \mathrm{Ax}_{2 \mathrm{n}}, \mathrm{Bx}_{2 \mathrm{n}+1}, \ldots \ldots \ldots$, converges to some point $\mathrm{z} \in \mathrm{X}$.

Proof: For simplicity let us take $d_{n}=d\left(y_{n}, y_{n+1}\right)$ for $\mathrm{n}=0,1,2, \ldots \ldots \ldots$.

We have

$$
\begin{aligned}
\mathrm{d}^{2}{ }_{2 \mathrm{n}+1}= & {\left[\mathrm{d}\left(\mathrm{y}_{2 \mathrm{n}+1}, \mathrm{y}_{2 \mathrm{n}+2}\right)\right]^{2}=\left[\mathrm{d}\left(\mathrm{Ax}_{2 \mathrm{n}}, \mathrm{Bx}_{2 \mathrm{n}+1}\right)\right]^{2} } \\
\leq \mathrm{c}_{1} \max \{[ & {\left.\left.\left[\mathrm{d}\left(\mathrm{Sx}_{2 \mathrm{n}}, \mathrm{Ax}_{2 \mathrm{n}}\right)\right]^{2}, \mathrm{~d}\left(\mathrm{Tx}_{2 \mathrm{n}+1}, \mathrm{Bx}_{2 \mathrm{n}+1}\right)\right]^{2},\left[\mathrm{~d}\left(\mathrm{Sx}_{2 \mathrm{n}}, \mathrm{Tx}_{2 \mathrm{n}+1}\right)\right]\right\} } \\
& +\mathrm{c}_{2} \max _{2} \mathrm{~d}\left(\mathrm{Sx}_{2 \mathrm{n}}, \mathrm{Ax}_{2 \mathrm{n}}\right) \mathrm{d}\left(\mathrm{Sx}_{2 \mathrm{n}}, \mathrm{Bx}_{2 \mathrm{n}+1}\right), \mathrm{d}\left(\mathrm{Ax}_{2 \mathrm{n}}, \mathrm{Tx}_{2 \mathrm{n}+1}\right) \\
& \left.\mathrm{d}\left(\mathrm{Bx}_{2 \mathrm{n}+1}, \mathrm{Tx}_{2 \mathrm{n}+1}\right)\right\}+\mathrm{c}_{3}\left\{\mathrm{~d}\left(\mathrm{Sx}_{2 \mathrm{n}}, \mathrm{Bx}_{2 \mathrm{n}+1}\right) \mathrm{d}\left(\mathrm{Tx}_{2 \mathrm{n}+1}, \mathrm{Ax}_{2 \mathrm{n}}\right)\right\} \\
\leq & \mathrm{c}_{1}\left\{\mathrm{~d}^{2}{ }_{2 \mathrm{n}}, \mathrm{d}^{2}{ }_{2 \mathrm{n}+1}\right\}+\mathrm{c}_{2}\left\{\mathrm{~d}_{2 \mathrm{n}} \mathrm{d}\left(\mathrm{y}_{2 \mathrm{n}}, \mathrm{y}_{2 \mathrm{n}-2}\right)\right\} \\
\leq & \mathrm{c}_{1} \max \left\{\mathrm{d}^{2}{ }_{2 \mathrm{n}}, \mathrm{d}^{2}{ }_{2 \mathrm{n}+1}\right\}+\mathrm{c}_{2}\left[\mathrm{~d}^{2}{ }_{2 \mathrm{n}}+\mathrm{d}_{2 \mathrm{n}} \mathrm{d}_{2 \mathrm{n}-1}\right] \\
\leq & \mathrm{c}_{1} \max \left\{\mathrm{d}^{2} \quad{ }_{2 \mathrm{n}}, \mathrm{d}^{2}{ }_{2 \mathrm{n}+1}\right\}+\mathrm{c}_{2}\left[\frac{3}{2} \mathrm{~d}_{2 \mathrm{n}}+\frac{1}{2} \mathrm{~d}_{2 \mathrm{n}-1}^{2}\right]
\end{aligned}
$$$$
\text { ...(1.5.1) }
$$

If $\mathrm{d}_{2 \mathrm{n}+1}>\mathrm{d}_{2 \mathrm{n}}$, inequality (1.5.1) implies $\mathrm{d}_{2 \mathrm{n}+1}^{2} \leq \frac{2 \mathrm{c} 2}{2-2 \mathrm{c} 1-\mathrm{c} 2} \mathrm{~d}_{2 \mathrm{n}}^{2}$ a contradiction, since $\frac{3 c 2}{2-2 \mathrm{c} 1-\mathrm{c} 2}<1$. Thus $\mathrm{d}_{2 \mathrm{n}+1} \leq \mathrm{d}_{2 \mathrm{n}}$ and 
This gives

$\leq \mathrm{c}_{1} \mathrm{~d}(\mathrm{Az}, \mathrm{z})^{2}+\mathrm{c}_{3} \mathrm{~d}(\mathrm{z}, \mathrm{Az})^{2}$

$\mathrm{d}(\mathrm{Az}, \mathrm{z})^{2} \leq\left(\mathrm{c}_{1}+\mathrm{c}_{3}\right) \mathrm{d}(\mathrm{z}, \mathrm{Bz})^{2}$

$\mathrm{d}(\mathrm{Az}, \mathrm{z})^{2}\left[1-\left(\mathrm{c}_{1}+\mathrm{c}_{3}\right)\right] \leq 0$, since $\mathrm{c}_{1}+\mathrm{c}_{3}<1$, we get $\mathrm{d}(\mathrm{Az}, \mathrm{z})^{2}=0$ or

$\mathrm{z}=\mathrm{Az}$. Therefore $\mathrm{S} \mathrm{z}=\mathrm{Az}=\mathrm{z}$. Since $\mathrm{z}=\mathrm{Az}=\mathrm{Bz}=\mathrm{Sz}=\mathrm{Tz}, \mathrm{z}$ is a

common fixed point of $\mathrm{A}, \mathrm{B}, \mathrm{S}$ and $\mathrm{T}$.

The uniqueness of common fixed point can be easily proved.

Now, we discuss our earlier example in the following two remarks to justify our result.

Remark-1: The pairs $(\mathrm{A}, \mathrm{S})$ and $(\mathrm{B}, \mathrm{T})$ are weakly compatible as they commute at coincident points $\frac{1}{5}$ and $\frac{1}{6}$

More over $\frac{1}{6}$ is the unique common fixed point of P,Q,S and $\mathrm{T}$.

Remark-2: In view of the earlier example Theorem2 is the generalization of theorem 1by virtue of weaker conditions such as weakly compatible mappings in place of compatible mappings; Associated sequence in place of completeness of metric space $(\mathrm{X}, \mathrm{d})$ and the continuity condition is being dropped.

\section{REFERENCES}

[1] B.Fisher and etal, "Common Fixed Point Theorems for Compatible Mappings", Internat. J. Math. \& Math. Sci, 3(1996), 451-456.

[2] G .Jungck, "Compatible Mappings and Common Fixed Points”, Internat. J. Math. Math. Sci .9(1986), 771-779.

[3] G.Jungck, B.E. Rhoades, Fixed Point for set valued Functions without Continuity, Indian.J.Pure.Appl.Math,3(1998), 227-238.

[4] G. Jungck., B.E. Rhoades, Fixed point for set valued functions without continuity, Indian J. Pure .Appl. Math, 3 (1998), 227-238.

[5] V.Srinivas, R.Umamaheshwar Rao, A Fixed point Theorem for Weekly Compatible Mappings, Journal of Mathematical Sciences \& Engineering Applications, 1(2007),41-48.

[6] V.Srinivas, R.Umamaheshwar Rao, Common Fixed Point Theorem for Four Self Maps, International Journal of Mathematics Research, 2 (2011), 113-118. 